\title{
On the Temperature Dependence of the Arrhenius Activation Energy for Hydroisomerization Catalyzed by Pt/Mordenite
}

\author{
A . van de R unstraat, J. van G rondelle, and R. A . van Santen \\ D epartment of Inorganic Chemistry and Catalysis, Faculty of Chemical E ngineering, E indhoven U niversity of Technology, P.O. B ox 513, \\ 5600 M B E indhoven, The N etherlands
}

R eceived J une 3, 1996; revised September 30, 1996; accepted D ecember 20, 1996

\begin{abstract}
A microkinetics simulation method, developed to analyze the kinetics of the hydroisomerization of $n$-hexane, was used to clarify the cause of the temperature dependency of the Arrhenius activation energy of thehydroisomerization of short alkanes on a Pt/mordenite catalyst. I t was shown that the model reproduces experimental data. Parameters have not been adjusted, but originate from independent experiments. Thechange toward lower activation energies at higher temperatures isshown to bedueto a decrease in the surface coverage of the active intermediate. This results in a change in the reaction order. The simulations prove that in the temperature regime considered neither intracrystalline diffusion nor single-file diffusion or a change in the rate-determining step is needed to explain the temperature dependence of hydroisomerization over $\mathrm{Pt} / \mathrm{mordenite}$ catalysts. The measured activation energy changes from the trueactivation energy for hydroisomerization when site coverage is high to the true activation energy minus the adsorption enthalpy of the reactant at low coverage.

(c) 1997 Academic Press
\end{abstract}

\section{INTRODUCTION}

In many cases and on different catalytic systems it has been found that the A rrhenius plot of overall reaction rate versustemperature is not a straight line. This change toward lower activation energy with increasing temperature can be explained in four different ways.

1. A change in the rate-determining step (RDS) for reactions proceeding by a sequence of different elementary reaction steps.

2. Intracrystalline diffusion (1). A t lower temperatures the surface reaction is rate determining, while at higher temperatures intracrystalline diffusion becomes rate limiting. In this case the true apparent activation energy is measured in the low-temperature region.

3. Single-file diffusion in one-dimensional zeolite pore systems. It has been proposed to effect kinetics especially at low temperatures (2). O ne of the most recent papers concerning this proposal was published by Liu et al. (3). Experimentally, the A rrhenius activation energy of the overall hydroisomerization of n-pentane over a Pt/H MOR cata- lyst was observed to decrease gradually with temperature. In the lower temperature range an activation energy of $145 \mathrm{~kJ} / \mathrm{mol}$ was measured. A t intermediate temperatures an activation energy of $112 \mathrm{~kJ} / \mathrm{mol}$ was measured, whereas at the highest temperature range the lowest activation energy $(55 \mathrm{~kJ} / \mathrm{mol})$ was observed. I t was proposed that at the lowest temperature the zeolite is filled with n-pentane, resulting in a reaction only using the acid sites close to the pore mouth. When the temperature is increased, the number of sites that can be used for the reaction is increased. The apparent activation energy that is measured in the lowtemperature range of the A rrhenius plot will, therefore, be higher. When all sites can be reached the lower, true apparent activation energy is obtained.

4. A change in surface coverage of the reactive intermediate at increasing temperature and thus the order of reaction. This option can be demonstrated by the well-known $H$ ougen-W atson rate equation of reactant $A$ (4).

$$
\begin{aligned}
R & =k_{\mathrm{RDS}} \cdot K_{\mathrm{ads}, \mathrm{A}} \cdot \theta_{\mathrm{empty}} \cdot p_{\mathrm{A}}=k_{\mathrm{RDS}} \cdot \theta_{\mathrm{A}} \\
& =k_{\mathrm{RDS}} \cdot \frac{K_{\mathrm{ads}, \mathrm{A}} \cdot p_{\mathrm{A}}}{1+K_{\mathrm{ads}, \mathrm{A}} \cdot p_{\mathrm{A}}},
\end{aligned}
$$

where $R$ is the rate of reaction, $k_{R D S}$ is the rate constant of the rate determining step, $\mathrm{K}_{\mathrm{ads}, \mathrm{A}}$ is the adsorption equilibrium constant of the reactant, $\theta_{\text {empty }}$ is the fractional coverage of empty surface sites, $p_{A}$ is the pressure of reactant, and $\theta_{\mathrm{A}}$ is the fractional coverage of reactive intermediates.

The fractional coverage of empty surface sites increases fromzero $\left(K_{a d s, A} \cdot p_{A} \gg 1\right)$ to one $\left(K_{a d s, A} \cdot p_{A} \ll 1\right)$ with temperature. This implies that the measured overall rate constant changesfrom the rate constant of the rate-determining step $\left(K_{R D S}\right)$ to this constant times the adsorption equilibrium constant of the reactant $\left(\mathrm{K}_{\mathrm{RDS}} \cdot \mathrm{K}_{\mathrm{ads}, \mathrm{A}}\right)$. A the same time the activation energy changes from the true activation energy ( $\left.E_{\text {act,true }}\right)$ to the true activation energy minus the adsorption enthalpy of the reactant $\left(E_{\text {act,true }}-\Delta H_{\text {ads }}\right)$. The order of reaction increases from zero to one.

This clearly demonstrates the need to know the real explanation for the curved A rrhenius plots since the 
determination of the true activation energy of the elementary step of isomerization will depend on the particular model used. Here we will present results of microkinetics simulations to investigate the kinetics of the hydroisomerization of $n$-hexane to clarify this debate. The dependence of the activation energy on temperature will be the focus of the analysis.

\section{METHOD}

A method similar to the microkinetics method as proposed by Dumesic et al. (5) was used to simulate the kinetics of the hydroisomerization of $n$-hexane. The reaction mechanism that was the basis of the simulations was divided into elementary reaction steps, according to the Weisz bifunctional mechanism (6). The simulations generate the steady-state concentrations of gas phase and surface species as a function of distance along the reactor, type of catalyst, and reaction conditions. The rates of elementary reaction steps, both forward and reverse, were calculated from fundamental data such as preexponential factorsand activation energies. The parameters of the elementary rate constants were taken from the literature, quantum chemistry or estimations which were restricted by thermodynamics. N one of these data, however, were derived from experiments on the hydroisomerization reaction itself. N o forward step was a priori assumed to be rate determining or at equilibrium with its reverse step. No diffusion was taken into account in the model. The most important parameters used in the model are given in Table 1.

The parameters described above and other input parameters, such as temperature and flow, concentrations of sites, and other catalyst characteristics, were used to generate a set of differential equations describing the gas-phase con- centrations and surface coverages as a function of position $z$ in the reactor. This set of differential equations was then converted to a set of algebraic equations by the steady-state approximation. The set was made independant by using mass balances and were then fed in classical catalytic engineering equations. Since surface species leave nor enter a volume element $A_{\text {reactor }} \Delta z$ ( $A_{\text {reactor }}$ being the reactor surface area), a zero-finding subroutine could be used to calculate the surface coverages. A Ithough surface coverages were used, the site balance could still be accounted for. D etails about the simulation will be presented elsewhere (7). It was shown previously that it accurately describes the overall rate of hydroisomerization of $n$-hexane under a wide range of conditions and on different zeolites $(7,8)$. This validated model is used to accurately simulate the kinetics of a Pt/H -mordenite catalyst as a function of temperature and make a quantitative comparison between experiment and simulation possible.

\section{RESULTS AND DISCUSSION}

The main results of the simulations at low and high pressures are given in Figs. 1 and 2, respectively. The temperature range applied is between 220 and $300^{\circ} \mathrm{C}$. The label $\mathrm{TO}_{\text {all }}$ in the figures means that all acid sites are taken into account to calculate the TOF (turnover frequency $\equiv$ mole n-hexane converted per acid site per hour). The label TO $F_{\text {alk }}$ means that the TOF is based on the number of sites that are occupied by a reactive intermediate during the reaction. This reactive intermediate in reactions catalyzed by acid zeolites is a n-alkoxy species (9). The number of $n$ alkoxy sites could be extracted from the simulations (see Table 2). This is a useful approach since the rate of product formation was already shown to be dependent on the

\section{TABLE 1}

Values or $R$ anges of the Most Important $D$ ata $U$ sed in the Simulation Model

\begin{tabular}{|c|c|c|c|c|}
\hline \multirow[b]{2}{*}{ R eaction } & \multicolumn{2}{|c|}{ Forward } & \multicolumn{2}{|c|}{ R everse } \\
\hline & $\begin{array}{c}E_{\text {act }} \\
(k J / m o l)\end{array}$ & $\begin{array}{l}\text { Preexponent } \\
\left(\mathrm{mol} / \mathrm{m}_{\mathrm{cat}}^{2} \cdot \mathrm{s}\right)\end{array}$ & $\begin{array}{c}E_{\text {act }} \\
(k J / m o l)\end{array}$ & $\begin{array}{l}\text { Preexponent } \\
\left(\mathrm{mol} / \mathrm{m}_{\text {cat }}^{2} \cdot \mathrm{s}\right)\end{array}$ \\
\hline A dsorption n-hexane & 10 & $14.6^{\mathrm{a}}$ & 81.9 & $4.91 \times 10^{8}$ \\
\hline D ehydrogenation $n-C_{6}$ & $40-55$ & $3.7 \times 10^{5}-1.2 \times 10^{8}$ & $36-55$ & $2.3 \times 10^{5}-5.3 \times 10^{7}$ \\
\hline Protonation to secondary & 50 & $1.5 \times 10^{8}$ & 130 & $2.1 \times 10^{11}$ \\
\hline \multicolumn{5}{|l|}{ I somerization n-alkoxy ${ }^{b}$} \\
\hline Secondary to secondary & 132.0 & $4.1 \times 10^{3}$ & 132.0 & $4.1 \times 10^{3}$ \\
\hline Secondary to tertiary & 140.4 & $4.1 \times 10^{3}$ & 176.5 & $4.1 \times 10^{3}$ \\
\hline Protonation to tertiary & 37 & $3.4 \times 10^{8}$ & 120 & $9.7 \times 10^{11}$ \\
\hline $\mathrm{H}$ ydrogenation iso- $\mathrm{C}_{6}$ & $26-45$ & $1.3 \times 10^{6}-6.9 \times 10^{7}$ & $40-55$ & $2.5 \times 10^{5}-3.7 \times 10^{7}$ \\
\hline D esorption isohexanes & 84 & $1.0 \times 10^{9}$ & 10 & $5.3 \times 10^{-4 a}$ \\
\hline \multicolumn{5}{|l|}{ D issociative adsorption } \\
\hline hydrogen on platinum & 2.4 & $1.0 \times 10^{-3 a}$ & 125 & $1.7 \times 10^{9}$ \\
\hline
\end{tabular}

\footnotetext{
${ }^{\mathrm{a}} \mathrm{D}$ imension of preexponential factor is $\mathrm{m}_{\text {gas }}^{3} / \mathrm{m}_{\text {cat }}^{2} \cdot \mathrm{s}$ since the resulting rates are per definition in $\mathrm{mol} / \mathrm{m}_{\text {cat }}^{2} \cdot \mathrm{s}$.
}

${ }^{b}$ Preexponential factor is multiplied by number of possibilities that give a particular reaction. 


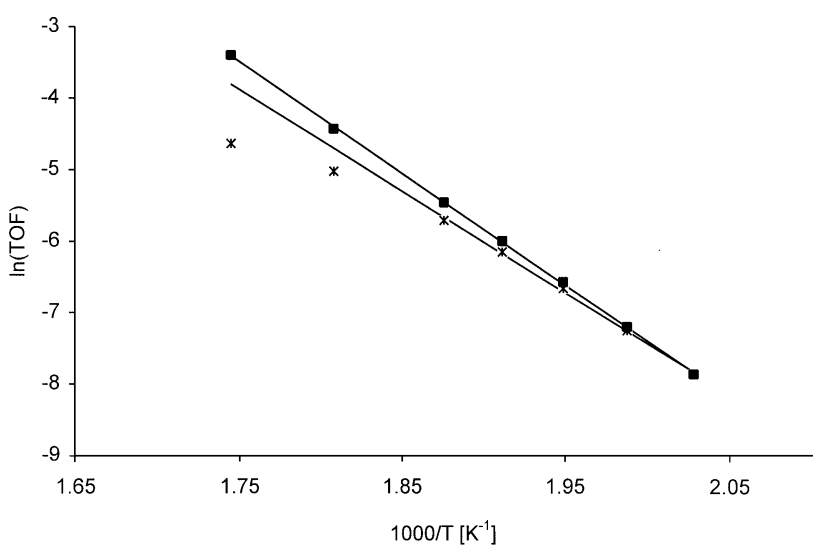

FIG. 1. Simulated A rrhenius plot at atmospheric pressure. TO $\mathrm{F}_{\text {all }}(*)$, $E_{\text {act }}=118.0 \mathrm{~kJ} / \mathrm{mol} ;$ TOF $_{\text {alk }}(\boldsymbol{\square}), E_{\text {act }}=129.7 \mathrm{~kJ} / \mathrm{mol}$.

surface coverage of reactive intermediate in $\mathrm{Eq}$. [1]. The activation energies are given in $\mathrm{kJ} / \mathrm{mol}$.

The simulated conversions were found to range from approximately $2 \%$ at 220 to $50 \%$ at $300^{\circ} \mathrm{C}$. Two different pressure regimes were used. The activation energies obtained in the range between 220 and $260^{\circ} \mathrm{C}$ are given in the figure legends. The low pressure value was within $10 \%$ of the value found in our experiments at atmospheric pressure. However, at both high and low pressures a temperaturedependent activation energy is obtained. The simulated activation energy decreases with increasing temperature from approximately 126 to $51 \mathrm{~kJ} / \mathrm{mol}$ at atmospheric pressure and from approximately 113 to $27 \mathrm{~kJ} / \mathrm{mol}$ at higher pressure.

Of the four explanations given in the Introduction, options 2 and 3 can immediately be ruled out as a potential explanation for the simulated results since no diffusion effects are taken into account in the model. This leaves a change in the rate-determining step or a change in reactant coverage as the explanation. Since the simulations yield the site coverages of all reactants and intermediates as well as

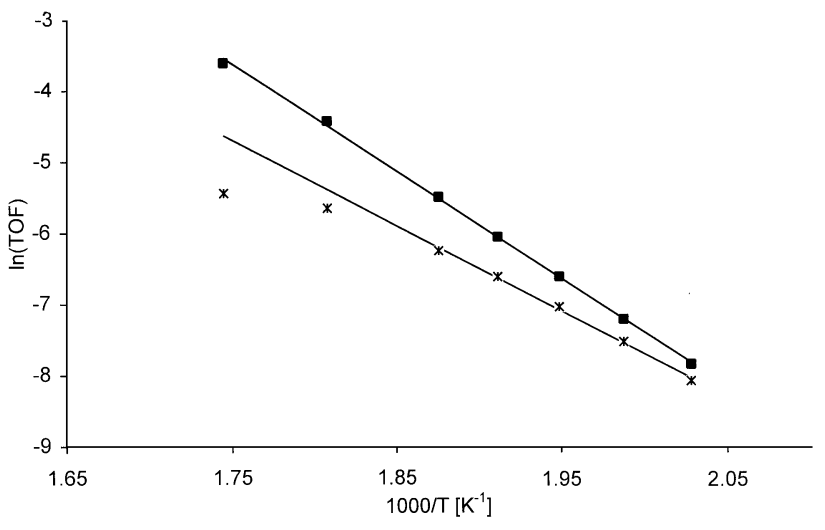

FIG . 2. Simulated $A$ rrhenius plot at 30 bar pressure. $T O F_{\text {all }}(*), E_{\text {act }}=$ $100.0 \mathrm{~kJ} / \mathrm{mol} ; \mathrm{TOF}_{\text {alk }}(\boldsymbol{\square}), \mathrm{E}_{\text {act }}=125.7 \mathrm{~kJ} / \mathrm{mol}$.
TABLE 2

Validation of Eq. [2], D ata at $240^{\circ} \mathrm{C}$

\begin{tabular}{ccccc}
\hline $\mathrm{p}_{n} \mathrm{c}_{6}$ (mbar) & $\begin{array}{c}\text { Total pressure } \\
\text { (bar) }\end{array}$ & $\theta_{n \text {-alkoxy }}$ & \multicolumn{1}{c}{$\mathrm{n}$} & Sum \\
\hline 36.0 & 1 & 0.930 & 0.108 & 1.04 \\
40.2 & 1 & 0.936 & 0.0997 & 1.04 \\
$3.1 \times 10^{3}$ & 30 & 0.664 & 0.194 & 0.86 \\
\hline
\end{tabular}

the rates of the individual elementary steps, it can be used to distinguish between the two explanations. No major shift in the rate-determining step as a function of temperature is found. However, we did see a significant change in the n-alkoxy coverage of the acidic sites of the zeolite. Conformation of option 4 as the true explanation is obtained, since a plot of the rate of reaction per occupied site $\left(T O F_{\text {alk }}\right)$ gives a straight A rrhenius plot (the lines marked by squares in Figs. 1 and 2). This demonstrates that the true activation energy does not change as a function of temperature. This confirms that there is no change in the rate-determining step.

In case of $\mathrm{L}$ angmuir- $\mathrm{H}$ inshelwood kinetics and $\theta \approx 1$ or $\theta \ll 1 \mathrm{E} \mathrm{q}$. [2] is approximately valid (10).

$$
n=\left(1-\theta_{n \text {-alkoxy }}\right)
$$

The orders of the reaction were simulated by changing the appropriate reactant partial pressure at $240^{\circ} \mathrm{C}$. The resulting orders were 0.14 and -0.11 at atmospheric pressure and 0.19 and -0.60 at 30 bar for $n$-hexane and hydrogen, respectively. A s Table 2 shows, Eq. [2] is approximately satisfied at those conditions.

A $n$ estimate for the order of the reaction in $n$-hexane at other temperatures can be obtained from the computed site coverage. Thus we find an order of reaction in $n$-hexane between $0.03\left(220^{\circ} \mathrm{C}\right)$ and $0.7\left(300^{\circ} \mathrm{C}\right)$ at atmospheric pressure and between $0.2\left(220^{\circ} \mathrm{C}\right)$ and $0.8\left(300^{\circ} \mathrm{C}\right)$ at 30 bar. It is also found that the site coverage and therefore the order according to Eq. [2] is approximately a linear function of the temperature.

We also recalculated the data of $L$ iu et al. in terms of TOF $\mathrm{Flk}_{\text {alk }}$ The published order of the reaction in n-pentane at $497 \mathrm{~K}$ was used to compute the n-alkoxy coverage from E q. [2]. A monotonously decreasing coverage in n-pentane as a function of temperature was assumed in agreement with the simulated temperature dependence. The resulting orders in n-pentane range from 0.18 at $177^{\circ} \mathrm{C}$ to 0.74 at $250^{\circ} \mathrm{C}$. In Fig. 3 the natural logarithm of both the TO $\mathrm{F}_{\mathrm{alk}}$ and the original experimental points are plotted against the reciprocal of the temperature. A gain a straight line is obtained when TOF alk is used. The value of the "true" activation energy found is slightly higher than our simulated values. This is due to the fact that the adsorption enthalpy of $n$-pentane is slightly lower than of $n$-hexane. 


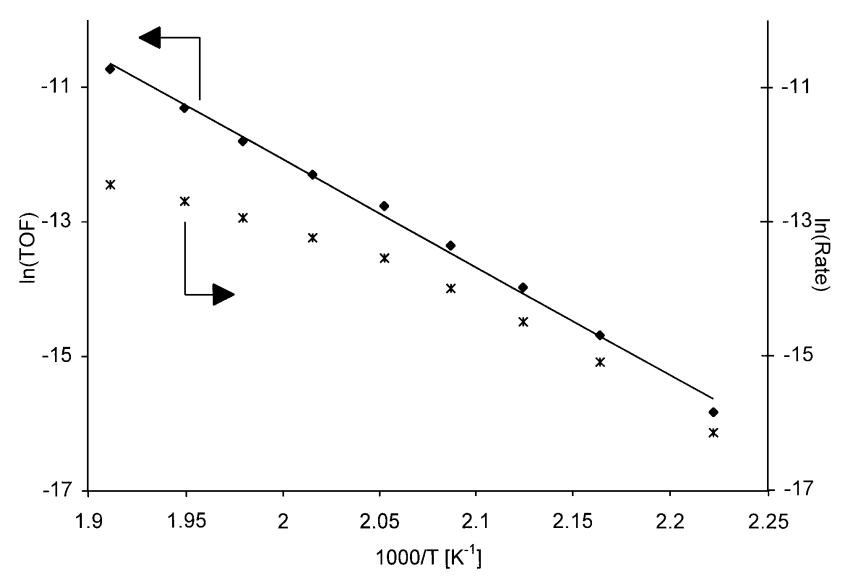

FIG. 3. R ecalculation of the data points of $L$ iu et al. (3). TO $F_{\text {alk }}(\bullet)$ ), $\mathrm{E}_{\mathrm{act}}=135 \mathrm{~kJ} / \mathrm{mol}$; Experimental points $(*)$.

A strong argument against diffusion being the main reason for the curved experimental A rrhenius plot is provided and the importance of the effect of changes in site coverage to the overall rate of reaction is illustrated.

\section{CONCLUSIONS}

We demonstrated from a quantitative comparison of simulated and experimental data that single-file diffusion limi- tation is not necessarily the explanation of the temperature dependence of the A rrhenius activation energy measured on a $\mathrm{Pt} / \mathrm{mordenite}$ catalyst. We propose that this dependence is mainly due to changes in the site coverages of protonated olefins.

\section{REFERENCES}

1. R oberts, G. W., and L amb, H. H ., J. Catal. 154, 364 (1995).

2. R ödenbeck, C., K ärger, J., and H ahn, K ., J. Catal. 157, 656 (1995).

3. Liu, H., Lei, G. D., and Sachtler, W. M. H., A ppl. Catal. 137, 167 (1996).

4. Froment, G. F., and B ischoff, K. B., "Chemical reactor A nalysis and Design," p. 70. Wiley, New York, 1990.

5. Dumesic, J. A., Rudd, D. F., A paracio, L. M., Rekoske, J. E., and Treviño, A. A., "The Microkinetics of Heterogeneous Catalysis," p. 114. A m. Chem. Soc., Washington, D C, 1993.

6. Weisz, P. B., in "A dvances in Catalysis and R elated Subjects" (D. D. Eley, P. W. Selwood, and P. B. Weisz, E ds.), Vol. 13, p. 157. A cademic Press, New York, 1963.

7. Van de R unstraat, A ., "A dsorption E ffects in A cid Catalysis by Zeolites." Thesis, E indhoven U niversity of Technology, 1997.

8. Van de R unstraat, A., Stobbelaar, P. J., Van G rondelle, J., A nderson, B. G., Van IJ zendoorn, L. J., and Van Santen, R. A ., in "Stud. Surf. Sci. Cat.," Vol. 105, "Progress in Z eolite and M icroporous M aterials" (H. Chon, S.-K. Ihm, and Y. S. U h, Eds.), p. 1253. Elsevier, A msterdam, 1996.

9. K azansky, V. B., and Senchenya, I. N., J. Catal. 119, 108 (1989).

10. Van Santen, R. A ., and N iemantsverdriet, J. W., "Chemical K inetics and Catalysis." Plenum, New York, 1995. 